\title{
Challenges Facing Women Caring for a Spouse Having Cancer Treatment: A Critical Literature Review
}

\author{
Patience Mbozi ${ }^{1,2^{*}}\left(\mathbb{D}\right.$, Cathy Ratcliff ${ }^{3}$, Dave Roberts ${ }^{4}$ \\ ${ }^{1}$ School of Nursing, Faculty of Health Sciences, Chreso University, Lusaka, Zambia \\ ${ }^{2}$ Zambia Oncology Nurses Society, Lusaka, Zambia \\ ${ }^{3}$ EMMS International, Edinburgh, Scotland \\ ${ }^{4}$ School of Nursing, Faculty of Health and Life Sciences, Oxford Brookes University, Oxford, UK \\ Email: *patiencembozi@gmail.com
}

How to cite this paper: Mbozi, P., Ratcliff, C. and Roberts, D. (2020) Challenges Facing Women Caring for a Spouse Having Cancer Treatment: A Critical Literature Review. Open Journal of Nursing, 10, 34-68. https://doi.org/10.4236/ojn.2020.101003

Received: November 21, 2019

Accepted: January 14, 2020

Published: January 17, 2020

Copyright ( 2020 by author(s) and Scientific Research Publishing Inc. This work is licensed under the Creative Commons Attribution International License (CC BY 4.0).

http://creativecommons.org/licenses/by/4.0/ (c) (i) Open Access

\begin{abstract}
Introduction: Cancer affects patients and families, especially female spouses. Female carers are affected emotionally, psychologically, spiritually and physically. Challenges while caring for husbands with cancer include: higher stress; poorer health-related quality of life; emotional strain; impaired immune system; low appetite; high blood pressure; depression and anxiety. Female spousal carers also experience satisfaction that they rendered appropriate care to their spouse. Aim: To analyse challenges facing women caring for a spouse on cancer treatment. Method: Systematic critical literature review through CASP. Thematic analysis of data. Results: 16 studies met the inclusion criteria; 12 were selected by critical analysis. 4 themes emerged: "Quality of marital relationship", "Effective communication", "Carers" burden and need for support', and "Coordination of care among providers". Discussion: 4 themes are discussed in detail and related to literature outside the review. Conclusion: Women caring for a spouse on cancer treatment is affected by the cancer, symptoms, hospital admission and caring. They withhold information from their spouse to protect him. They have poor quality of life and poor health. HCP rarely recognize their role or needs.
\end{abstract}

\section{Keywords}

Female Carers, Challenges, Men with Cancer, Cancer

\section{Introduction}

\subsection{Background}

Cancer is the second leading cause of death worldwide [1] [2]. 14 million new 
cases and 8 million cancer-related deaths worldwide were reported in 2012; over $60 \%$ of new cancer cases occur in Africa, Asia, and Central and South America, and $70 \%$ of the world's cancer deaths occur in these regions [3]. Cancer is increasing in Sub-Saharan Africa [4].

This review highlights challenges that women face while caring for their husbands with cancer, by critically reviewing and analysing relevant literature. The researcher is a registered nurse who has practised for 10 years; she qualified as a palliative care nurse and was head of a Palliative Care Unit for 5 years. The unit sees patients with long-term incurable diseases such as cancer and HIV. It is in the capital city and patients travel from rural areas for treatment; this, plus the low socio-economic status of patients and Zambia, means that patients present to the unit with advanced cancer. The unit aims to render palliative care services to patients and their families, and enable them to have a good quality of life. It is essential to understand the challenges and benefits of spouses caring for their husbands with cancer, because they are often neglected and their needs not considered, as care centres on patients alone [5].

Over the last 20 years in Zambia, there have been increases in cervical cancer, Kaposi's sarcoma and eye cancer [6]. In a 16 million population, numbers of cancer patients accessing cancer services increased from 25 in 2006 to 2431 in 2017 [7]. In 2011-2015, there were 3048 cancer cases in females and 2147 in males, and in 2014-2017 there were 7147 cancer cases in females and 4764 in males, a total of 17,787 over 2011-2017 [8]. The most common men's cancer is Kaposi's sarcoma followed by prostate cancer, cancer of the eye, Non-Hodgkin's lymphoma, colorectal cancer, oesophageal cancer, stomach cancer and liver cancer; the most common women's cancer is cervical cancer, followed by breast cancer, Kaposi's sarcoma, eye cancer, Non-Hodgkin's lymphoma, colorectal cancer, oesophageal cancer and ovarian cancer [8].

Cancer affects carers emotionally, psychologically, spiritually and physically [9] [10]. Female carers experience greater stress; poorer health-related quality of life, impaired immune system, loss of appetite, raised blood pressure, depression and anxiety [9] [10]. On the other hand, they also experience satisfaction at rendering appropriate care to their spouse [11]. This study seeks to understand challenges facing women caring for a spouse having cancer treatment.

\subsection{Statement of the Problem}

Cancer affects the family; if the breadwinner is a patient, there is a financial impact [11] [12] [13] [14]. Cancer causes a family to change its daily routines, as the disease devastates everyone in the family [14]. Cancer affects patients' quality of life and increases morbidity and mortality [13]. However, there is no data explaining challenges of female carers during care of their husbands with cancer, as many studies discuss couples [15] [16] [17] [18]. This review establishes knowledge on challenges of women caring for husbands. 


\subsection{Justification for the Study}

Carers' experiences depend on the nature of their relationship with the patient [11]. Blanchard (1997) recommends more research to understand better female carers' experiences so that healthcare professionals can develop interventions and guidelines to support and prepare spousal carers to care for loved ones with cancer [13]. Women are more involved in care of their spouses than men are, performing more household chores and personal care than men do [19]. Knowledge of their challenges will provide evidence for health workers, for global practice and for hospitals' policies on carers and their roles.

\subsection{Research Question}

"What are the challenges facing women caring for a spouse having cancer treatment?"

\section{Research Objectives}

1) To appraise literature on challenges facing women caring for a spouse on cancer treatment, and thereby identify main themes on challenges of female spousal carers.

2) To evaluate the research and identify gaps in the existing body of knowledge.

3) To discuss implications for an oncology setting and make recommendations.

\subsection{Outline of This Paper}

This paper has seven chapters, including this introduction. The other chapters present preliminary literature review; research methodology and methods of critical literature review; results; analysis; discussion; and conclusions and recommendations. The preliminary literature review gives an overview of literature on needs of carers. The methodology of this research is critical literature review, a comprehensive and systematic search, evaluation and analysis of the literature. The methods involved reviewing 31 studies, of which 16 discussed challenges of carers caring for their patient with cancer; of these, 12 were selected for detailed analysis: 5 prospective cohort studies, 3 qualitative studies and 4 literature review articles. These were critically analysed using CASP, examining study populations, designs and methodologies. 4 themes were found: "Quality of marital relationship", "Effective communication", "Carers" burden and carers' need for support', and "Coordination of care among providers". This review concludes that carers' role and needs are not considered by Health Care Providers (HCP), and advocacy is needed to influence policy to integrate carers to the healthcare system. Challenges of carers of cancer patients must be anticipated, identified and managed. HCP must be educated to appreciate the value and role of female carers of cancer patients, their needs and how to support them. HCP must help carers and their patients to communicate and express feelings openly between 
each other, and carers must be educated to understand their role for patients and how they can support them.

\section{Preliminary Literature Review}

The preliminary literature review identified needs for information, emotional support, practical support with daily life, and good patient medical care.

\subsection{Need for Information}

Carers of cancer patients want to be honestly informed about everything happening to their patients from the time they are diagnosed [20] [21] [22] They want information about diet, lifestyle adjustments, how to support patients and how to have time to discuss their condition with Healthcare Personnel (HCP) and other carers in a similar situation [22]. When a patient is diagnosed with cancer, they have several problems, due to the symptoms, side-effects of treatment and disease progression and recurrence; these must be told in good time to both carer and patient [22] [23] [24]. Carers may not want to talk about the illness with HCP, and instead may opt to talk about other things such as hobbies and family issues [25]. Patient problems may overwhelm both patients and carers emotionally and socially, and they have to be made aware early of how to deal with this [22]. Several factors contribute to carers being under-informed of their patients' illness: not being near the patient during doctors' visits, being unable to read what is in the file, being unable to ask HCP, and not understanding medical language [22]. It is important to meet carers' need for information.

\subsection{Need for Emotional Support}

Carers need emotional support at critical times: diagnosis, disease progression, and cancer recurrence [22]. Emotional support to carers differs according to cultures and socio-economic status [25]. Carers need enough time and a comfortable, private environment while being told of the diagnosis and treatment plan, as they need to be relaxed [22]. Carers expect HCP to be aware of their psychological and emotional needs and devise appropriate measures to help or refer to others [11] [20]. Carers do not want a lot of information during the diagnosis period as it is very hard for them to process it due to distress [26]. Several factors hinder carers from receiving adequate emotional support, including their inability to express their fears and concerns to HCP, lack of knowledge of who to contact and lack of openness about the disease between carer and patient [22]. Carers need emotional and psychological support.

\subsection{Inadequate Formal and Informal Support}

Carers often experience additional responsibilities of caring, compounding existing roles in the household, and are insufficiently supported in hospital [26]. Carers and their patients normally cope with support available, using mainly informal support networks of families and friends, to organise finances, transport 
patients and manage household resources. Formal support includes support from specialized HCP [27], but carers do not normally know where to get support in the hospital and if it is suitable for them as they are not fully informed about it [26]. Practical support that carers need includes transport, nursing care assistance, pain management drug administration, paid leave from employment, financial support, cleaning and continuous supplies of catheters, colostomy bags and incontinence pads [22] [26]. Factors that lead to carers not obtaining practical support include the increased caring burden and inadequate information on availability of services and how to access them [22] [23]. Caring for a cancer patient is overwhelming because it is added to existing household roles: hence the need for extra support.

\subsection{Good Medical Care for Patients}

Carers need to see that their patient is receiving good medical care [22]. They accompany patients to doctors' visits to support them, learn about the patient's care plan, and ensure that patients give accurate information to HCP. Carers feel satisfied when helping monitor their patient's condition [22] [27]. Sometimes carers do not receive medical support due to their fear that reporting dissatisfaction with care will negatively affect the patient and fear of talking about sensitive issues [22] [27]. Carers need the best possible medical care for their patient and good communication.

\section{Methodology and Methods}

\subsection{Research Methodology of Critical Literature Review}

Critical literature reviews are vital to maintaining standards of evidence-based practice and healthcare [27]. A literature review is a comprehensive study to interpret the results of literature relating to a specific topic [28] [29]. For a literature review to be undertaken, there is need first to identify the research question, then perform a literature search and analyse the significant literature systematically [30]; the more specific the research question, the more focused the literature review [31]. Literature reviews can be systematic, critical or narrative. A critical literature review is useful where there is no agreement and no available evidence in the literature body, but limitations include: the fact that not all relevant literature may be included in the study due to an incomplete search strategy and no access to unpublished "grey" literature, and personal opinions and biases affecting summaries made from literature reviews [32]. Consequently, literature reviews are important to develop new insights, summaries and a comprehensive picture while reviewing a number of studies in the literature. A good critical literature review involves a researcher comprehensively and systematically searching, evaluating and analysing the literature [29]. Therefore, this research has a specific research question which enabled the researcher to be specific and focused in the literature search, and a critical literature review was done comprehensively as an appropriate research methodology to answer research aims, syn- 
thesise data and draw conclusions appropriately.

\subsection{Methods}

The methods involved reviewing 31 studies, of which 16 discussed challenges of carers caring for their patient with cancer; of these, 12 were selected for detailed analysis: 5 prospective cohort studies, 3 qualitative studies and 4 literature review articles.

\subsection{Search Strategy-Electronic Database Search}

A first search was conducted during the preliminary literature review to identify gaps in the literature and a second to identify articles for review. The researcher performed database searches on PUBMED, CINAHL and Journals for health and social care (Table 1).

\section{Search Terms Used}

Medical Subject Headings (MeSH) were used to identify key terms and synonyms. Search terms for the Boolean search were: female carers, challenges, men with cancer and cancer (Table 2).

To manipulate key search terms Boolean logic "OR", "NOT", "AND" and truncations such as "car»" were used to bring out different nouns, spelling and synonyms [28].

\subsection{Boolean Searches 1 and 2}

Boolean searches 1 and 2 were done with the key terms using Advanced Search and All Articles (Tables 1-4).

In Boolean search 2, other search terms were added to further narrow the search (Table 4). The different searches were combined (\#1 AND \#2 AND \#3 AND \#4 AND \#5) to identify results.

Table 1. Databases used.

\begin{tabular}{|c|c|}
\hline DATABASE & Description \\
\hline PubMed & Life sciences and biomedical topic data \\
\hline $\begin{array}{l}\text { CINAHL (Cumulative Index to } \\
\text { Nursing and Allied Health Literature) }\end{array}$ & Nursing and allied healthcare data \\
\hline Science Direct Journals-Freedom Collection (OBU) & European Journal of Oncology Nursing \\
\hline
\end{tabular}

Table 2. Boolean search 1 terms.

\begin{tabular}{cc}
\hline Boolean Search 1 & \\
\hline Term 1 & Cancer OR men with cancer \\
Term 2 & Female partners NOT male partners \\
Term 3 & Car* OR caring OR care \\
Term 4 & Cancer therapy ${ }^{*}$ OR cancer treatment OR cancer treatment modalities \\
\hline
\end{tabular}


Table 3. Illustrating Boolean search 1.

\begin{tabular}{ccc}
\hline Database & Search Terms & No. of Hits \\
\hline CINAHL & $1+2+3+4$ & 31 \\
Pubmed & $1+2+3+4$ & 285 \\
Science Direct Journals-Freedom Collection (OBU) & $1+2+3+4$ & 350 \\
\hline
\end{tabular}

Table 4. Illustrating Boolean search 2.

\begin{tabular}{ccc}
\hline Database & Search Terms & No. of Hits \\
\hline CINAHL & $1+2+3+4+5$ & 5 \\
PubMed & $1+2+3+4+5$ & 143 \\
Science Direct Journals-Freedom Collection (OBU) & $1+2+3+4+5$ & 229 \\
\hline
\end{tabular}

\subsubsection{Narrowing the Search}

Boolean logic AND, OR and NOT were applied further to narrow the search and produce relevant results concerning female carers' experiences of caring for patients with cancer only (Table 5).

\subsubsection{Inclusion and Exclusion Criteria}

Studies included in the critical literature review were relevant to the research question (Table 6).

\subsubsection{Additional Means of Searching}

In addition to the electronic database search results, PubMed and Science Direct had a provision to show similar articles and some articles were extracted from there, to give a thorough search. This enabled the researcher to get literature that did not come out of the search process and it allowed for a thorough and complete search.

\subsection{Selection of Data for the Review Process}

The inclusion and exclusion criteria were applied to select final results for critical literature review. Of 16 studies, 12 were appraised using Critical Appraisal Skills Programme (CASP) (Table 7).

\subsection{Data Analysis and Synthesis Method}

\subsubsection{Use of Critical Appraisal Framework}

The articles finally selected for review were critically analysed using CASP tools [33] [34] [35]: Qualitative study tool, Cohort Study tool and systematic review tool.

\subsubsection{Data Analysis}

\section{Step 1: Familiarization with the data}

The articles were read multiple times for familiarity with data results, and to note similarities and inconsistencies of articles [28] [30] [36] [37]. 
Table 5. Illustrating "narrower terms" in the search processes.

\begin{tabular}{ccc}
\hline Database & Search Terms & Hits \\
\hline CINAHL & $1+2+3+4+5$ NOT dementia & 3 \\
& OR HIV OR heart disease OR delirium & \\
PubMed & $1+2+3+4+5$ NOT dementia & 100 \\
& OR HIV OR heart disease OR delirium & \\
Science Direct Journals - & $1+2+3+4+5$ NOT dementia & 176 \\
Freedom Collection $(\mathrm{OBU})$ & OR HIV OR Heart disease OR delirium & \\
\hline
\end{tabular}

Table 6. The inclusion and exclusion criteria applied.

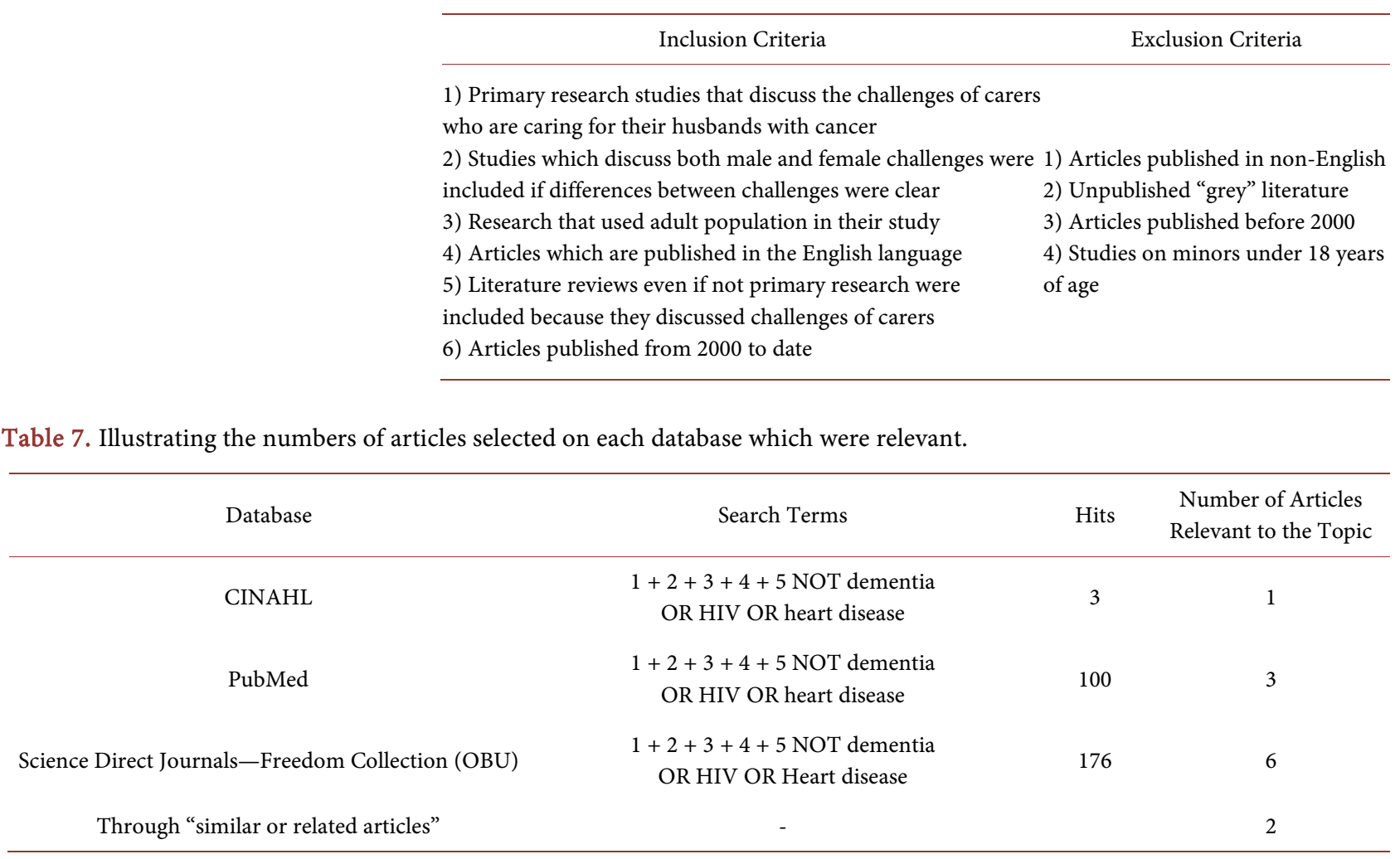

Table 7. Illustrating the numbers of articles selected on each database which were relevant.

\section{Step 2: Generation and assigning of codes}

Codes were generated from the main findings and discussion points of each article and again after summarizing articles' main outcomes. Then codes were assigned to each outcome.

\section{Step 3: Developing themes}

Similar codes were grouped together and organized to enable the development of themes. The process was repeated several times until all codes were grouped to develop provisional themes.

\section{Step 4: Comparing codes and themes}

The themes were visited several times to ensure that the themes were in accordance with the codes. Some new themes and codes were developed in the process.

Step 5: Definition and naming of themes 
Developed themes were individually examined and narrowed further to avoid repetitions and ensure they represented the data. Names were given to 12 themes.

\subsubsection{Data Synthesis}

Data synthesis of findings is the final stage of the research process to develop the research report. Literature findings were compared for similarities and inconsistencies. Inconsistent data was reviewed in detail for quality of research, which explained the few inconsistencies found.

\section{Results}

31 studies were found in the search. 16 articles that specifically discussed challenges of carers caring for their patients with cancer were considered. 12 of these were relevant and of good quality: 5 prospective cohort studies, 3 qualitative studies and 4 literature review articles. These were critically analyzed using CASP, ensuring that studies had good methodology and quality. Assessing the quality of studies included examining the study populations, designs and methodologies. Table 8 summarises the critical analysis.

Table 8. Data synthesis.

\begin{tabular}{|c|c|c|c|c|}
\hline Author/Date & Aim of the Study & $\begin{array}{c}\text { Type of } \\
\text { Study/Information }\end{array}$ & Main Findings/Conclusion & Strengths and Limitations \\
\hline $\begin{array}{c}\text { Pitceathly } \\
\text { and Maguire } \\
\text { (2003) }\end{array}$ & $\begin{array}{l}\text { To address prevalence of } \\
\text { psychiatric morbidities and } \\
\text { psychological distress } \\
\text { among carers especially } \\
\text { female }\end{array}$ & Literature review & $\begin{array}{l}\text { Spouses who use avoidance technique as a } \\
\text { coping mechanism indicates that the individual } \\
\text { has psychological issues; age, gender specifically } \\
\text { female and personality compound the problem }\end{array}$ & $\begin{array}{l}\text { The review was narrative; the } \\
\text { researcher reported findings of } \\
\text { different literature reviewed } \\
\text { rather than critically analysing }\end{array}$ \\
\hline $\begin{array}{l}\text { Mossin and } \\
\text { Landmark } \\
\quad(2011)\end{array}$ & $\begin{array}{l}\text { To explore experiences of } \\
\text { spouses who are present } \\
\text { with their loved ones in } \\
\text { hospital during last days } \\
\text { before death }\end{array}$ & Qualitative study & $\begin{array}{l}\text { The main classification for the findings is } \\
\text { Maintaining presence, either for one's own sake } \\
\text { or for the patients' sake to ensure that the } \\
\text { couple's relationship is maintained despite the } \\
\text { husband being admitted to hospital }\end{array}$ & $\begin{array}{l}\text { The time period when } \\
\text { interviews took place was } 2 \\
\text { weeks post bereavement as } \\
\text { participants may still going } \\
\text { through grief }\end{array}$ \\
\hline $\begin{array}{l}\text { Moser et al. } \\
\quad(2013)\end{array}$ & $\begin{array}{l}\text { To assess the emotional } \\
\text { distress levels on cancer } \\
\text { patients and their partners } \\
\text { and how these relate to } \\
\text { each other }\end{array}$ & Cohort study & $\begin{array}{l}\text { Prevalence rates of anxiety and distress upon } \\
\text { diagnosis varied between } 15 \% \text { and } 36 \% \text {; rates } \\
\text { were lower in patients who are either female or } \\
\text { male than in female carers. } \\
\text { Clinically significant depression rates were } \\
\text { higher in female carers than female patients, } \\
\text { male patients and male carers. Over time } \\
\text { depression declined in all groups. } \\
\text { Follow-up assessment of a small group of female } \\
\text { carers showed that } 3 \% \text { still suffered clinically } \\
\text { significant distress, compared to patients of both } \\
\text { sexes and male partners }\end{array}$ & $\begin{array}{l}\text { Mortality rates were high in } \\
\text { male patients, which caused a } \\
\text { reduction in numbers of follow } \\
\text { up of patients. There were high } \\
\text { rates of curative cancers; in spite } \\
\text { of this being a positive outcome, } \\
\text { results of the cohort could be } \\
\text { affected as patients and their } \\
\text { spouses would not have } \\
\text { emotional distress noted in } \\
\text { follow up assessments }\end{array}$ \\
\hline
\end{tabular}




\section{Continued}

To explore ideas of spousal carer and cancer patient

Li and Loke dyads in terms of mutuality Literature review and identify directives for future research

To find out the barriers

Kimberlin et and facilitators of patients al. (2004) and carers in relation to pain management

To explore the needs,

Sercekus et al. challenges and ways of

coping of carers of cancer Aualitative study patients on chemotherapy treatment

To explore cancer patient

Stenberg et al.family carers' physical and (2010) psychosocial health Literature review problems

To evaluate qualities of

Kim and attachment of spouses of

Carver (2007) cancer patients who are

Cohort study now survivors

To evaluate the

psychological distress of carers and their partners

Braun et al. with cancer, while

measuring the contribution Cohort study of caring burden, marital satisfaction and attachment orientation to depression in carers

To describe patterns of

Nijboer et al. experiences of carers of

(2000) patients with cancer over a period of 6 months

They assessed the quality of data from a published journal while considering impact factors and

Good communication between couples facilitates systematic analysis of extracted congruence between the female carer and the data. A language bias occurred patient, thereby strengthening their intimacy and as articles in the review were improving the caring experience written in English only. Publication bias also existed in that only published articles were considered

Convenience sampling of participants volunteering for the study meant that subjects were

Patient education and information exchange between patients and healthcare workers enable active participation of patients and female carers in the care process, and improve coordination of care and relationships among HCP

Female carers of cancer patients experience many problems and display many coping strategies, and HCP should be able to identify these

The burden related to caring emerged due to many responsibilities that female carers had in addition to their role as carers not representative of other populations of couples dealing with cancer. Racial differences among couples were not assessed

The study is of good quality Data collection, interpretation and analysis were appropriately done

Authors did not assess the validity and reliability of instruments they used in their review to determine symptoms. Self-reported problems' frequency was not quantified in the review

Female carers' orientation to their relationship to the husband plays a very important role in It is not explicitly indicated how carers' provision of care services or perception of participants were followed up care provision as being burdensome

Advanced cancer patients have high prevalence of depression, which can be predicted by the use of the Subjective caring burden and relational variables which are the female carers' attachment orientations and marital dissatisfaction

The study did not produce significance differences in terms of sex differences, age demographics and duration of the relationship between carers and their patients with cancer

The effect of female carers' burden on their self-esteem and on interrupted diary roster decreased throughout the period of 6 month after discharge. On the other hand, the effect on no or Lack of Family Support, financial problems, and Loss of Physical Strength The follow up period of 6 months was inadequate to ascertain fully carers' experiences remained constant over 6 months 


\section{Continued}

To evaluate the effects of Morgan et al. pain and financial concerns (2011) as stressors on the QOL of Cohort study cancer patients and their spouses

The couple's relationship quality is directly affected by intensity of pain but the quality of the relationship with the female carer may lessen the negative effect of pain
Mortality rates were high in male patients, causing a reduction in numbers of patients followed up. There were high rates of curative cancers, affecting results of the cohort, as patients and their spouses would not show emotional distress in follow up assessments

\subsection{Study Aims}

The aims of the 12 studies were similar, as most aimed to explore the challenges of "couples" or "carers" dealing with cancer [15] [16] [17] [18] [38]-[44]. Many studies were qualitative. Literature reviews were included for data about cancer patient carers' challenges [38] [40] [41] [44].

\subsection{Study Population}

Studies included in the review did not specifically target women's challenges, but couples' challenges, but differences in their challenges were described, enabling the researcher to capture information of interest [16] [18] [39] [40] [41] [43]. Five studies looked beyond the couple to family members by focusing on family carers' challenges but did not exclude the couple's experience [15] [17] [38] [42] [44]. All studies clearly stated their population description.

\subsection{Recruitment Methods}

Articles included in the review recruited participants from communities, rural comprehensive centres, a chemotherapy unit and outpatient clinics in hospitals. The 5 cohort studies and 3 qualitative studies had similar recruitment strategies. The 4 literature reviews did not specify the recruitment strategies as they are secondary data research articles. One of the 4 reviews did not have a section highlighting the methodology, search strategy, and illustrating how the reviewed articles were selected [38]. 2 qualitative studies used convenience sampling which enables the researcher to find participants who are readily available to participate in the study [28] [30].

\subsection{Sample Size}

To achieve validity, reality and confidence in the results, large samples are normally taken in quantitative research [28] [30]. Sufficient large numbers of participants are required for cohort studies to enhance confidence of the results [28] [30]. In qualitative research studies, snowball, theoretical and purpose samplings are used and the sample size is relatively small to extract data which is manageable from the interviews from a targeted population [28] [30]. The five cohort studies had sufficient numbers at first follow-up, except two which had poor 
follow-up due to high cure rates of participants or high mortality rates of participants [16] [45]. One study did not give an explicit description of how participants were followed up (Kim and Carver 2007) [18], causing low numbers of participants who were followed up, instead of equal numbers. 2 out of 3 Qualitative studies used purposive sampling method which was appropriate for the study [39] [42], while the other one used convenience sampling of participants who volunteered for the study, and therefore the subjects were not representative of the other populations of couples dealing with cancer [43].

\subsection{Study Design}

The 12 articles had their aims clearly defined and their study designs matched the aims.

\subsubsection{Qualitative Studies}

Three out of 12 studies used qualitative research methodology [39] [42] [43]. All 3 collected their data in an appropriate way through interviews which were audio-recorded. Mossin and Landmark (2011) explored the challenges of spouses present with their loved ones in hospital during their last days before death, but interviews were scheduled to take place 2 weeks post-bereavement, when one could still be under intense grief and may not give appropriate responses [39]. Kimberlin et al. (2004) qualitative study aimed to find out barriers and facilitators of patients and carers in relation to pain management, but convenience sampling of participants who volunteered for the study was done and the subjects were not representative of other populations of couples dealing with cancer, and racial differences were not assessed among participants [43]. Sercekus et al. (2014) qualitative study explored the needs, challenges and ways of coping of carers of cancer patients on chemotherapy [42]. The study is of good quality, and data collection, interpretation and analysis were appropriate.

\subsubsection{Prospective Cohort Studies}

Five out of 12 studies used prospective cohort methodology [15] [16] [17] [18] [45]. In 2 prospective cohort studies, appropriate methodology was used, but mortality rates were high in male patients which caused a reduction in numbers of follow-up of patients. Moreover, high rates of curative cancers were noted; in spite of this positive outcome, results of the cohort could be affected as patients and their spouses would not have emotional distress in follow-up assessments [16] [45]. Braun et al. (2007) cohort study evaluates the psychological distress of carers and their partners with cancer, while measuring the contribution of caring burden, marital satisfaction and attachment orientation [17]. The researchers' hypothesis was supported by the study results, but the study did not produce significant differences in sex, age and duration of relationship between carer and patient with cancer. Kim and Carver (2007) cohort study evaluated the qualities of attachment of spouses of cancer patient survivors. Researchers hypothesized 
that the security of attachment closely relates to the frequency of spouse involvement in patient care, hence low levels of carer burden [18]. Gender role or orientation of carers' relationship to the partner plays an important role in carers' provision of care to the partner with cancer or perception of care provision as burdensome. However, the study does not state how participants were followed up.

\subsubsection{Literature Review}

Critically appraising literature means assessing whether the review was done systematically and examining how articles in the review were selected, critically analysed and synthesised [28]. Four out of 12 studies used literature review methodology [38] [40] [42] [44]. Li and Loke (2013) Literature review explored ideas of spousal carer and cancer patient dyads in terms of mutuality and identify directives for future research [40]. However, a language bias occurred as the articles were written in English language only and publication bias also existed in that only published articles were considered in the review. Li et al. (2013) explored experience of carers both female and male, while reviewing differences for their spouse with cancer using the stress process [41]. However, the researcher focused only on published research rather than unpublished 'grey' research, a weakness which could imply that some relevant literature may have been left out. Pitceathly and Maguire (2003) addressed the prevalence of psychiatric morbidities and psychological distress among carers especially female, and conversely, their review was more narrative, reporting findings of different literatures reviewed rather than critically analysing [38].

\subsection{Methodological Procedures}

The authors in the 5 cohort studies ensured that before utilizing measurement scales for the study, they were adequately measured [15] [16] [17] [18] [45]. However, Kim and Carver (2007) developed one more measurement scale just for their study and this could mean that it is not validated [18]. Objective measures were used to obtain information from participants in all cohort studies. Potential measurement error can be reduced by use of subjective measures instead of objective measures [28].

\section{Analysis}

Common themes were developed from research results through thematic analysis. These themes are presented and discussed in the following subsections while answering the research question.

\subsection{Thematic Analysis and Key Terms Identification}

4 themes arose from critical analysis: "Quality of marital relationship", "Effective communication", “Carers" burden and carers' need for support' and "Coordination of care among providers" (Table 9 \& Table 10). 
Table 9. Illustrating the arrangement of common themes and codes.

\begin{tabular}{|c|c|}
\hline Theme & Codes \\
\hline Quality of marital relationship & $\begin{array}{l}\text { A) Masking feelings } \\
\text { B) Marital difficulties } \\
\text { C) Importance of a good marital relationship } \\
\text { D) Reciprocal influence } \\
\text { E) Carer patient congruence } \\
\text { F) Attachment orientation } \\
\text { G) Personal satisfaction } \\
\text { H) End of life carers' experiences }\end{array}$ \\
\hline Effective communication & $\begin{array}{l}\text { A) Communication between a couple } \\
\text { B) Communication between the HCPP and the couple } \\
\text { C) Couples' needs for information }\end{array}$ \\
\hline $\begin{array}{l}\text { Carers' burden and } \\
\text { carers' need for support }\end{array}$ & $\begin{array}{l}\text { A) Caring tasks } \\
\text { B) Physical effects } \\
\text { C) Social effects } \\
\text { D) Psychological effects } \\
\text { E) Carers' need for support } \\
\text { F) Carer coping mechanisms }\end{array}$ \\
\hline $\begin{array}{c}\text { Coordination of } \\
\text { care services among HCP }\end{array}$ & $\begin{array}{l}\text { A) Improving provider relationship-building skills } \\
\text { B) Hospital conditions } \\
\text { C) Inadequate equipment } \\
\text { D) Overcoming time barriers } \\
\text { E) Involvement of patients and carers in the healthcare practice } \\
\text { F) Education of patient and carer } \\
\text { G) Fear of use of pain medication }\end{array}$ \\
\hline
\end{tabular}

Table 10. Common themes and codes and number of times they appear in the articles.

\begin{tabular}{|c|c|c|c|c|c|c|c|c|c|c|c|c|c|}
\hline Themes & Codes & 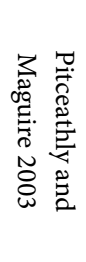 & 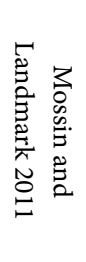 & $\begin{array}{l}5 \\
2 \\
2 \\
2 \\
\tilde{N} \\
0 \\
\omega\end{array}$ & 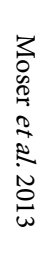 & 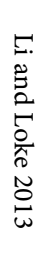 & 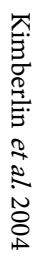 & 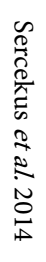 & 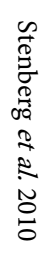 & 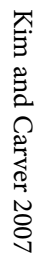 & 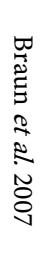 & 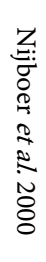 & 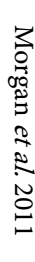 \\
\hline \multirow{6}{*}{$\begin{array}{l}\text { Quality of marital } \\
\text { relationship }\end{array}$} & 1A. Masking feelings & & & & & & & $\checkmark$ & & & $\checkmark$ & & \\
\hline & 1B. Marital difficulties & $\checkmark$ & $\checkmark$ & $\checkmark$ & & $\checkmark$ & & & & & $\checkmark$ & & $\checkmark$ \\
\hline & 1C. Reciprocal influence & & & & & $\checkmark$ & & & & & & & \\
\hline & 1D. Carer patient congruence & & & & & $\checkmark$ & & & & & & & \\
\hline & 1E. Attachment orientation & $\checkmark$ & & $\checkmark$ & & & & & & $\checkmark$ & $\checkmark$ & & $\checkmark$ \\
\hline & 1F. Personal satisfaction & & $\checkmark$ & $\checkmark$ & & & & & & & & & \\
\hline \multirow{4}{*}{$\begin{array}{c}\text { Effective } \\
\text { communication }\end{array}$} & 2A. Communication between couple & & $\checkmark$ & & & $\checkmark$ & $\checkmark$ & $\checkmark$ & & & & & \\
\hline & 2B. Communication between HCP \& couple & & $\checkmark$ & & & $\checkmark$ & $\checkmark$ & $\checkmark$ & & & & & \\
\hline & 2C. Couple needs for information & & $\checkmark$ & & & $\checkmark$ & $\checkmark$ & $\checkmark$ & & & & & \\
\hline & 2D. Education of patient and carer & & & & & & & $\checkmark$ & & $\checkmark$ & & & \\
\hline \multirow{4}{*}{$\begin{array}{l}\text { Carers' burden } \\
\text { and need for } \\
\text { support }\end{array}$} & 3A. Caring tasks & & & & & $\checkmark$ & & $\checkmark$ & $\checkmark$ & $\checkmark$ & & & \\
\hline & 3B. physical effects & & & & $\checkmark$ & & & $\checkmark$ & $\checkmark$ & & & $\checkmark$ & \\
\hline & 3C. Social effects & & & & $\checkmark$ & & & $\checkmark$ & $\checkmark$ & & & $\checkmark$ & \\
\hline & 3D. Psychological effects & & & & $\checkmark$ & & & $\checkmark$ & $\checkmark$ & & & $\checkmark$ & \\
\hline
\end{tabular}




\section{Continued}

\begin{tabular}{|c|c|c|c|c|c|c|c|c|}
\hline & 3E. Carers' need for support & & $\checkmark$ & & & $\checkmark$ & $\checkmark$ & $\checkmark$ \\
\hline & 3F. Carer coping mechanisms & & $\checkmark$ & & & $\checkmark$ & $\checkmark$ & $\checkmark$ \\
\hline \multirow{5}{*}{$\begin{array}{l}\text { Coordination } \\
\text { of care services } \\
\text { among HCP }\end{array}$} & 4A. Improving provider relationship skills & & & $\checkmark$ & $\checkmark$ & & & \\
\hline & 4B. Hospital conditions & $\checkmark$ & & $\checkmark$ & $\checkmark$ & & & \\
\hline & 4C. Inadequate equipment & $\checkmark$ & & $\checkmark$ & $\checkmark$ & & & \\
\hline & 4D. Overcoming time barriers & $\checkmark$ & & $\checkmark$ & $\checkmark$ & & & \\
\hline & 4E. Patients \& carers involved in healthcare & & & $\checkmark$ & $\checkmark$ & & & \\
\hline
\end{tabular}

\subsubsection{Theme 1: Quality of Marital Relationship}

6 articles are focused on quality of marital relationship [16] [17] [38] [39] [40] [41].

1) Importance of a good marital relationship

Couples dealing with cancer with a healthy marital relationship had a good Quality of Life (QOL), whereas those who do not have a good marital relationship or are single experience poor mental and physical health, carer burden, distress and a low QOL and most may need external support; relationship quality of close friends and intimate partners has a positive influence on QOL outcomes [17]. The couple's relationship quality is directly affected by intensity of pain and quality of the relationship may lessen negative effects of pain; the QOL of both patient and partner is affected by financial concerns but the relationship quality is not affected [16].

Li et al. (2013) which aimed to explore experiences of carers both female and male while reviewing differences for their spouse with cancer using the stress process, suggests that the illness state of the patient and care demands were considered primary stressors, while spouses' roles and their marital relationships which comprises social and emotional support, employment attributes during illness, unstable financial life, poor self-perception, disturbed sleep pattern, interruption in life schedule and lifestyle were considered secondary stressors [41]. However, the researcher focused only on published research rather than unpublished "grey" literature, a weakness which means that some relevant literature may have been left out (Bowling 2014) [30].

Li and Loke (2013) revealed that marital adjustments were seen in couples who supported each other during the illness and marital satisfaction was closely associated with patients' physical and mental health status and not the carers' physical and mental health status [40]. The study suggests that emotion-focused coping, role adjustment and marital satisfaction are interrelated factors that influence reciprocal support between a spouse and her husband with cancer. The study concludes that patients' problems in adjusting their roles emerge from their hopelessness and spouses' issues with role adjustment, which in turn emerged from spouses' level of marital satisfaction and their own role alteration problems [40].

2) Masking feelings 
Sercekus et al. (2014) reveal that carers of cancer patients mask feelings which were articulated through difficulties in handling emotions expressed by the patient and hiding their own feelings [42]. Carers expressed how difficult it was to talk to their relatives about the cancer disease and its extent as they were afraid of how the patient may react and what they could do to handle the situation [42]. Participants expressed fear of showing how they feel about the disease status as they were afraid that their patients may become sad. On the other hand, some participants mentioned fear of showing happiness, as they were afraid that their relatives would misunderstand them [42]. Braun et al. (2007) recommend that the importance of the couple relationship to the welfare of carers and their partners with cancer needs to be acknowledged by healthcare personnel (HCP) as they render their health services [17].

\section{3) Personal Satisfaction}

Mossin and Landmark (2011) reveals that personal satisfaction is voiced by spouses of cancer patients, as being there for their husbands was satisfying and they said that they could not miss that opportunity for anything [39]. Their experience allowed them to cope well during bereavement and preserve good memories of their husbands. This correlates with Li et al. (2013) which also shows that personal growth is a positive sign seen in women more than in men [41]. The study also revealed that spouses of men with advanced cancer disease were very anxious compared to spouses of men with cancer disease which has not advanced; this was more related to the condition of the patients and high demands of care by the patient [41].

a) Personal desire to care for a partner

Mossin and Landmark (2011) report that the uncertainty of spouses about their role in the whole healthcare system and in the hospital was disheartening, as spouses thought that they were not being recognized, and talked less of identifying their emotions as they took care of their husbands [39]. The study sample in this case is a group of Norwegian women and generalisation of results may be limited as there could be cultural differences with other countries. Mossin and Landmark (2011) reported that despite lack of recognition in their role as carers, women overlooked the way they were considered by HCP and were there for their husbands throughout the hospital stay and had such great desire to support their husbands [39]. Male partners stated that support from spouses was positive, as it maintained their identity and self-esteem and women felt an active part of the team in care of their husbands [39]. Li and Loke (2013) state that higher self-efficacy, rated in terms of physical activity in both patients and spouses, was associated with the couple's good adjustment towards the illness, less anxiety, reduced carers' strain and good mental wellbeing [40]. However, the review revealed that spouses with lower self-esteem viewed the role towards their patients negatively. Similarly, Mystakidou et al. (2013) states that high anxiety levels are more common in carers with low self-esteem than in carers with high self-esteem [46]. 


\section{4) Attachment orientation}

Kim and Carver (2007) evaluate qualities of attachment of spouses of survivor cancer patients, and assess aspects of care provided to patients and how carers provided the care [18]. They explore the relationship between attachments to patient care tasks and sex differences (Kim and Carver 2007) [18]. They hypothesised that the security of attachment closely relates to the frequency of spouse involvement in patient care, and hence low levels of carer burden. On the other hand, they hypothesised that avoidance of attachment is closely related to lower frequency of spouse involvement in patient care, and hence high levels of carer burden. They go on to assume that attachment anxiety closely relates to frequency of involvement in patient care but high levels of caring burden [18]. Kim and Carver (2007) study was done on participants who were fluent speakers of English or Spanish, and therefore generalisability of the results is limited to carers who are educated, affluent and Caucasian carers [18]. The study reports that carers with attachment avoidance have problems in rendering emotional care to their partners with cancer, and these carers would benefit from health education interventions, good communication, and empathetic listening to help them provide emotional support to their partners, and should be advised to use family or community resources available to them [18]. Braun et al. (2007) recommend that HCP should be sensitive in dealing with carers, as their role as carers is based on their attachment orientation, and high levels of depression are associated with higher carers' attachment anxiety and avoidance [17]. Morgan et al. (2011) suggest that carers of advanced cancer patients have a high prevalence of depression, predicted by the use of the subjective caring burden and relational variables which are the carers' attachment orientation [16].

\section{5) End of life carer experiences}

One study brought out an important issue of end of life experience of carers [39]. Mossin and Landmark (2011) qualitative study explored experiences of spouses who are present with their loved ones in the hospital during their last days before death. Different themes emerged from the study, the main one being maintaining presence, either for one's own sake or for the patient's sake to ensure that the couple's relationship is maintained despite the husband being admitted to hospital [39]. Spouses were not even willing to be at home and the spouse's presence seemed to calm the patient and give them the desire to be with their wife all the time [39]. Support to patients was regarded as direct support and was appreciated, in that good quality of care to the patient showed that the couple was supported and the patient received good pain and symptom control [39]. Mossin and Landmark (2011) reported that despite their husbands' illness, none of the spouses discerned that their husbands would die during the admission in the hospital, and understood being there for their husbands as a normal extension of married life [39]. Termination was a very difficult time for spouses, as it not only stopped the caring role of the women but also the end of their marital relationship [39].

6) Summary of theme 1 
The studies showed that cancer has a definite effect on the female carers' and patients' marital relationship. Good prior marital relationships have a positive impact on the couple, while negative effects propagated by marital dissatisfaction show increased distress in both the female carer and patient. Female carers tend to withhold information from their spouses by not communicating openly with them as silence is perceived as protecting the patient from additional stress. The studies showed that interactions between female carers and patients with cancer are directly affected by the cancer disease itself, the symptoms, the period of admission in the hospital and caring roles. Despite this, female carers appreciate being present at the end of life because they felt that they had an opportunity to say goodbye to their loved one despite carer challenges.

\subsubsection{Theme 2: Effective Communication}

2 issues arose: communication within a couple and communication between HCP and couple.

1) Communication within couples

Li and Loke (2013) explore ideas of spousal carer and cancer patient dyads in terms of mutuality and directions for future research [40]. The results are grouped under three mutuality concepts: communication, reciprocal influence and carer-patient congruence. Factors that influence good communication between spouse and husbands with cancer are prior good marital relationships, good couple communication about cancer disease and treatment, good prior memories of their relationships, couples having sufficient time for each other, previous good problem-solving skills, couple's mutual plans for the future, marital adjustments and low distress [40].

\section{2) Communication between healthcare personnel and couple}

Kimberlin et al. (2004) explore the barriers and facilitators of patients and carers in relation to pain management and gives suggestions to improve communication with patients, carers and providers [43]. Improving provider relationship-building skills is a major theme, under which two behaviours emerged: Inhibiting behaviours and Facilitating behaviours. Inhibiting behaviours comprise behaviour of healthcare providers, who tend to create communication barriers between them and patients and carers, such as insensitive care and demeaning communication. Facilitating behaviours include healthcare providers' behaviours that create a caring relationship between providers and patients to facilitate effective communication [43]. Sercekus et al. (2014) discuss communication problems between couples dealing with cancer and HCP, as carers and patients complain that they are not fully informed and educated on the patient's condition, treatment options, treatment side-effects, extent of disease and course of treatment [42]. This correlates with Kimberlin et al. (2004) which states that communication is another area where carers feel left out, even when their patients request their involvement in the conversation and it is frustrating for carers when their patient is found depressed because of the information given to them without the carer present to give appropriate care and support [43]. 
Li and Loke (2013) show that the Quality of Life (QOL) of couples dealing with cancer is improved with good communication from the HCP around cancer [40]. A reduction in uncertainty and the negative outcome of the illness improve patients' and spouses' QOL. Mossin and Landmark (2011) reveal that HCP behaviour, such as talking to spouses or good communication skills and physical contact such as greeting and showing concern, contribute positively to the patient and their spouses, as they see the team's consideration towards them [39]. Conversely, Kimberlin et al. (2004) highlight that carers complain that healthcare providers were not allowing them to be knowledgeable about their patient's illness, and this is frustrating [43].

3) Summary of theme 2

HCP tend to ignore female carers of cancer patients by informing only the patients and not informing and updating carers about patients' information, a practice that is so discouraging to female carers, because it is important to keep carers well informed about their patient's illness, extent and current state. Good communication skills of reassurance, greeting and showing concern have positive impacts on female carers and on patients with cancer.

\subsubsection{Theme 3: Carers' Burden and Need for Support}

1) Carer tasks

The 6-month cohort study of Nijboer et al. (2000) reveals that the effect of carer burden on carers' self-esteem and on interrupted diary roster decreased over 6 months [15]. Carers derived less self-esteem from caring, and care offered to patients was perceived as less interruptive over the 6 months. However, Stenberg et al. (2010) report that the burden related to caring emerges due to many responsibilities that carers have and in addition to their role as carer [44]. Caring consumes a lot of time as patients need support in activities of daily living, emotions, company, monitoring symptoms and transporting the patient to hospital [44]. Carers find it hard to balance this with meeting needs of other family members who are not sick [44].

2) Psychological effects

a) Psychological problems experienced during caring

Carers of advanced cancer patients have high prevalence of depression, which can be predicted by use of the subjective caring burden and relational variables which are the carers' attachment orientations and marital dissatisfaction; high levels of depression are associated with higher carers' attachment anxiety and avoidance and $49 \%$ of spousal carers reported psychological effects, including feelings of sadness, powerlessness, depression, fear of loss of a loved one, distress, anxiety, shock, hopelessness, suffering, weakness, guilt, irritability in the caring process, and mood disturbances [17]. Emotional distress is evident in carers who perceive the patient's illness negatively irrespective of the patient's condition or the patient's view of the disease status [38]. The correlates with Li and Loke (2013) who report that psychological distress is evident in couples, as they have depression, stress and poor physical health, closely related to age of the 
patient, negative perceptions of outcomes of the illness by the spouse, high level of hopelessness in the patient and poor health in the patient [40]. Spouses who use avoidance technique as a coping mechanism have psychological problems, and age, female gender and personality compound the problem [38]. This relates to Moser et al. (2013) which assesses emotional distress in cancer patients and their partners and how these relate to each other; their study was done over 3 years, after cancer diagnosis [45]. Prevalence rates for anxiety and distress upon diagnosis varied from $15 \%$ to $36 \%$, and rates were lower in patients who are either male or female than in their spouses [45]. Depression rates which were clinically significant were higher in female partners than female patients, male patients and male partners, and over time depression declined in all groups [45]. After 3 years, a follow-up assessment on a small group of female partners, $3 \%$ of the sample population, discovered that they still suffered from distress which was clinically significant, compared to patients of both sexes and male partners [45].

b) Psychological support

Carers raise the need for psychological support from their sick partners, HCP and family and friends, to help them cope during the caring process [42]. Spouses state that being around their husband during his hospital stay is necessary as it helps them feel at peace and calm, showing that spouses suffer a great deal when their husbands are suffering from cancer, and allowing them to be around their husbands during a hospital stay is necessary to their psychological wellbeing [39]. Braun et al. (2007) recommend that HCP create, plan patient and implement carers' couple interventions, integrating them to healthcare [17].

\section{3) Physiological effects}

Stenberg et al. (2010) explore cancer patient family carers' physical and psychosocial health problems reported in literature, and discover how carers describe their responsibilities and problems [44]. Carers of cancer patients experience physical problems such as pain, loss of strength, sleep problems, appetite loss and loss of weight [44]. This correlates with Sercekus et al. (2014) who explore the needs, challenges and ways of coping of carers of cancer patients on chemotherapy treatment. Carers go through physiological effects of caring, such as weight loss, grief, fatigue, hypertension, headaches, insomnia, eczema and stress [42]. Loss of physical strength remains constant during a 6-month cohort and its effect is perceived more negatively in females than in men; carers' experiences should be looked at in both negative and positive ways, as these experiences change over time, and inter- and intra-individual patterns must be studied through different subgroups of carers [42].

4) Social effects

a) Socio-economic problems

Nijboer et al. (2000), describing experiences of carers of patients with cancer over 6 months, reveals that lack of family support and financial problems remained constant over 6 months [15]. This is similar to findings of Sercekus et al. (2014) qualitative study, which reports that participants experience social effects, 
including quitting their jobs, role strain, financial difficulties, isolation and restrictions on social life because of increased care needs of the patient and increased burden of care [42]. Financial difficulties arise due to costs of transport, and effects of quitting employment and transport difficulties arise due to long distances from home to hospital where cancer treatment is received, as it is difficult for patients to commute to and from hospital, causing them to require admission to ease the process of receiving cancer treatment (Sercekus et al. 2014) [42]. Quality of life of both spouses and husbands with cancer is improved by adequate social support [40]. Sercekus et al. (2014) recommend social support networks to be availed to carers [42].

5) Carers' coping mechanism

Similarities and differences in perceptions of health-related Quality of Life between patients and their spouse are seen in coping strategies, disease evaluation, disease adjustments and protective buffering [40]. Coping strategies are used differently between female carers and their patients. In terms of disease evaluation, carers view their patients' good physical and psychosocial function as an indicator of patients' improvement, unlike the way patients view themselves [40]. Sercekus et al. (2014) adds that coping behaviours that relieved carers and were exhibited by them include turning to God, doing housework such as cleaning that keeps them busy, taking walks, playing games on the computer, crying, thanking God, being with friends, watching movies, performing handiworks and praying during the caring process [42]. Nijboer et al. (2000) state that self-esteem in male carers did not change over time but a less positive influence on self-esteem was reported by female carers and this could be due to differences in coping styles, emotional attentiveness and caring roles of women and men [15]. Pitceathly and Maguire (2003) identify that informal support has a positive effect on carers' coping styles [38].

a) Carers' need for support

Mossin and Landmark (2011) report that support, a major factor that emerged from the study, is revealed when spouses voice a need to be supported by their sick husbands, family and the healthcare team, and this support plays a positive role in their experience [39]. Despite being sick, women felt a need to be supported as they were being supported at home, because that made them feel good and maintained their role and value [39]. Nonetheless, Kim and Carver (2007) suggest that gender role or orientation of carers' relationship to the partner plays a very important role in carers' provision of care to the partner with cancer or perception of care provision as burdensome [18]. Nijboer et al. (2000) add that female and younger carers are the most vulnerable carers who need a plan of healthcare and support [15]. Braun et al. (2007) study recommends that HCP constantly assist carers in their demanding role of caring [17].

6) Summary of theme 3

Female carers of husbands with cancer experience poor quality of life, poor physical and mental health and lack of satisfaction of life. They tend to expe- 
rience serious negative physiological, social and psychological effects, due to their caring role and the devastating and overwhelming nature of the cancer disease. Taking care of cancer patients is absorbing and restricts one's ability to fulfill social responsibilities. Due to the longevity of cancer treatment and the process families go through during cancer diagnosis and treatments, female carers normally reach a stage of financial crisis. Fears, anxiety and tension are evident in female carers, due to their concerns about their patient's condition, the nature of the disease and how society understands it.

\subsubsection{Theme 4: Proper Coordination of Care among Providers}

1) Complaints about healthcare personnel and hospital conditions

Patients and carers feel really discouraged and helpless when HCP caring for them go into disagreements and lack cooperation and proper communication; HCP must be open to second opinions outside consultation times for work to move smoothly [43]. Participants complain of problems that arise from the healthcare system such as: difficulties with small clinics in their residential area when they request referral to tertiary centres to continue receiving cancer treatment; long waiting times for treatment due to inadequate human resources; uncomfortable conditions of the hospital; and not enough equipment such as wheelchairs to ease patients' movement [42]. Kimberlin et al. (2004) reports that participants complain of time barriers such as waiting for appointment dates, excessive waiting before seeing HCP, waiting for telephone calls to be returned and inadequate time during meetings between patient and HCP, and these discouraged patients [43]. Participants complain that generally in hospital, needs of patients are regarded as more important than needs of carers, and this makes spouses think their own need to rest is not considered [39].

2) Involvement of the patient and carer in healthcare

Kimberlin et al. (2004) recommend that information exchange be improved between HCP and couples dealing with cancer [43]. It highlights a need for greater recognition of patients as sources of information. The study was conducted through diaries, in which patients documented when pain medication was administered and side-effects, their questions and suggestions, and type of care which was helpful to them. This helped patients focus on their needs as they could not forget the type of questions to ask the doctor during review clinics. Kimberlin et al. (2004) suggest that information exchange between patients and healthcare workers enables active participation of patients and carers in care and the whole healthcare system, improving coordination of care and relationships among HCP, overcomes time barriers and addresses fears of pain medication use [43].

\section{3) Education of patients and carers}

Improving education of patients and carers is a dominant theme, as couples dealing with cancer express the need to understand the disease itself, its prognosis, signs and symptoms, pain medication choices, available treatment, treatment modalities, treatment side-effects and their management, care of the patient at 
home, and care for carers at home to enable them to be well informed [43]. This is in line with Sercekus et al. (2014), which adds that patients and carers must be informed to ensure adherence of the patient to treatment prescribed and self-care activities [42]. All participants stress the importance of allowing them to participate in decision-making about care, ask questions and research their disease and available treatments, to enable them to have control over their illness and be part of the medical care [43].

\section{4) Fear of use of pain medication}

Morgan et al. (2011) assess effects of pain and financial concerns as stressors, the nature of the couple's relationship and the coping style of spouses as outcomes and mediators, to determine the direct effect on carers' QOL and that of their patients [16]. The intensity of pain has a direct negative effect on the patient's QOL and not on the partner's QOL [16]. Kimberlin et al. (2004) suggests that a number of fears of use of pain medication emerged from interviews, including: fear of opioids, addiction, being judged, being seen as a weakling for admitting pain, loss of control and expressing need for medication [43]. These were largely expressed by patients. Carers expressed the fear of feeling that they are unable to manage pain anymore and of thinking that opioids actually hasten the patient's death.

5) Summary of theme 4

If HCP do not recognise the important role that female carers play for their patients and in the healthcare system, or their needs, then carers may feel intimidated. When female carers are actively involved in patient care, adequately informed about their patients' illness and treatment plan, and involved in decision-making, a good relationship develops between them and HCP and they become active members of the healthcare team.

\section{Discussion}

\subsection{Interpretation of the Results}

The critical literature review explored and analysed challenges facing women caring for a spouse having cancer treatment. Key themes which emerged from the data include: "quality of marital relationship", "effective communication", "burdens related to caring" and "proper coordination of care among health care providers".

\subsubsection{Theme 1: Quality of Marital Relationship}

The quality of a marital relationship has a great influence on the way couples relate to each other when dealing with difficult situations like a cancer diagnosis [16] [17] [38] [39] [40] [41]. A healthier marital relationship enhances couples' QOL, improves their physical and mental health and reduces caring burdens on the carer; pain and financial burdens have no negative effects on a couple with a good marital relationship [16] [17] [38] [39] [40] [41]. Quality of marital relationship is not really appreciated in practice as HCP tend to be too "patient- 
focused" while forgetting some fundamental aspects to enhance the patient's wellbeing and the spouse's caring experience. Carers of cancer patients tend to feel isolated and not supported by HCP because HCP are too patient-focused and do not share patient information with carers [47].

The "patient focus" makes HCP not appreciate presence of the patient's close family near the patient, and sometimes these family members are constantly chased out of wards with the argument that the patient should receive total nursing care and be nursed in a quiet environment, because HCP regard carers as barriers to good care, which is actually very wrong, as patients themselves want to be around their loved ones, to receive moral support [5].

1) Masking feelings

Masking feelings are common in clinical practice as carers choose to "die inside" rather than talk openly with their patient or express their emotions openly with their patient; this causes a "conspiracy of silence" between a couple, where each is pretending to the other without talking or expressing their feelings. Houldin (2007) reports that carers have problems balancing emotions, such as when getting angry or sad as they are afraid that the patient may misinterpret the emotions. Moreover, attending to needs between patient and family, especially showing children love and affection, is another reported challenge [48]. Spouses of cancer patients have serious difficulties in honestly expressing their feelings about the cancer disease, handling negative emotions expressed by the patient and talking about the cancer disease with the patient, as they are uncertain how the patient may react. On the other hand, some spouses had difficulties in smiling or showing happiness with other members of their family as they are afraid of being misunderstood [17] [42].

\section{2) Personal desire and satisfaction in caring for a partner}

Carers, especially women, feel satisfied at being there for their partners and mostly treasure the time spent with them. Women do not really mind how they are viewed in hospital as long as they are there for their patient, as they understand the responsibility to care as part of their role as wives and to maintain their identity and self-esteem [39] [41]. On the other hand, carers of cancer patients often decide not to let their situation of caring weigh them down, and try to maintain their hope, self-efficacy and readiness for death of their loved one [48] [49]. Carers go through a difficult situation after learning the diagnosis of their patient, but try to balance their emotions and try to behave as if everything is normal despite the complexity of the situation [49] [50].

\section{3) Attachment orientation}

Carers with attachment avoidance experience problems rendering emotional care to their partners with cancer, and these carers would benefit from health education interventions, good communication, and empathetic listening to help them provide emotional support to their partners; High levels of depression are associated with higher carers' attachment anxiety and avoidance. Carers should be advised to use family or community resources available to them. Carers of 
advanced cancer patients have a high prevalence of depression [16] [17] [18] [19] [49]. Due to women's attachment to their husbands, they are there for their partners because they want to observe their marital vows and commitments promised to each other and this leads carers to be there for their partners till death [51] [52].

\section{4) End of life carer experiences}

Termination is a very difficult time for spouses, as it stops not only women's caring role but also their marital relationship. Women appreciated being present at the end of life because they felt that they had an opportunity to say goodbye to their loved one [39]. Fears regarding the future and loss of the loved one to take care of the children fully are the main contributing factors to high levels of anxiety during caring, especially during end of life care [53] [54]. Pearce et al. (2006) also state that the meaning of life and death is always questioned by patients and carers and they both experience helplessness, anger and sadness at their situation [55]. On the other hand, carers often fail to plan for the future at the end of life and are highly aware that their loved one will die soon (Olson 2014) [56].

\subsubsection{Theme 2: Effective Communication}

\section{1) Communication barrier between couples}

Couples dealing with cancer have challenges during the illness if they did not have prior good communication and coordination to make plans together, good problem-solving skills and create memories before the illness. This communication barrier causes couples to be unsure what to communicate to each other, causing silence during caring [40] [43]. Lack of or poor communication is evident in couples dealing with cancer because of the negative impact of the diagnosis on a couple and previous communications problems within a couple [57]. In clinical practice, there are instances where spouses ask HCP to withhold certain information from the patient, in an attempt to protect their patient, as they are afraid that when the patient knows the truth, they will be stressed and depressed; therefore, the spouse hears the information, keeps it and withholds it from the patient. Couple assessment must be included in healthcare especially for couples dealing with cancer, so that problems identified can be managed and couple interventions implemented accordingly.

2) Communication barriers between HCP and patient and carer

There are existing communication barriers between HCP and patients and their spouses, as information is not honestly, freely, empathetically and adequately given to them regarding patient condition, treatment options and sideeffects, extent of disease and course of treatment. Some HCP only give information to patients without consideration of carers [40] [43]. Many HCP think withholding the truth from the patient means relieving the patient of additional stress without knowing that they are causing more harm than good. Other HCP give the information but in a sarcastic and intimidating manner which is not helpful to the patient. Hence training in effective communication should be in- 
cluded in clinical practice so that HCP can break bad news to patients and practise truth-telling in an effective and efficient manner. In clinical practice, carers, especially spouses, need to know what is going on with their patient, and once this is ascertained, they become an active part of the healthcare system, very calm, easily adjusting to the situation and coping well, because they have knowledge of the patient's illness. Truth-telling becomes vital, and false hope must never be practised. However, this truth must be said in a skilled manner, in a breaking bad news session. Carers of cancer patients need to be informed about their patient's condition and how they can perform basic needs assessments and care at home [58] [59]. Due to lack of recognition of carers' roles in hospital, carers become inactive and demoralized [53].

\subsubsection{Theme 3: Burdens Related to Caring}

Caring for a cancer patient is not easy as the role consumes a lot of time and interrupts daily activities. In addition to being at the bedside and giving moral and emotional support, carers actively assist with self-care of the patient, monitor the patient's symptoms and find ways to source income to feed and transport the patient to and from hospital. Carers find themselves in a vulnerable situation where they equally need support, not only from HCPs, but also from the patient himself, family and the community at large. Houldin (2007) reports that responsibilities of carers of cancer patients increase during the caring process as they fail to balance and plan priorities in the household and marital relationship strain [48]. The caring role of carers of cancer patients receiving treatment negatively affects their QOL and wellbeing [60]. Carers of cancer patients experience permanent alterations of their normal schedules due to the caring burden [48] [61].

In practice, especially where human resources are inadequate, carers end up giving total nursing care to the patient and HCP only give the treatment where and when it is due. Therefore, HCP must be able to provide nursing care to the patient and relieve carers to concentrate on other things that are less stressing, to relieve them.

\section{1) Psychological effects}

The caring role is psychologically distressing; in addition to the burden of care, carers experience psychological problems which indicate that they are in a poor state of mind as they sit at the bedside. Female carers are so vulnerable and have suffered from anxiety and depression in addition to the roles of caring [17] [39] [42]. Sanders et al. (2006) which reports that carers often go through ongoing psychological distress and worries regarding the cancer diagnosis, prognosis and chance of recurrence [62]. Mystakidou et al. (2013) report that higher levels of anxiety are more common in spouses of advanced cancer patients and female carers than in male carers [46]. Likewise, Andrade et al. (2001) reveal that anxiety is scored higher in women than in men, even than those who have been with their patients for a long time [63]. Female carers love to be around their husbands despite their length of stay in the hospital for psychological wellbeing 
[17] [39] [42]. Carers undergo psychological and social distress and need appropriate interventions to support them [64]. Psychosocial interventions given to carers and their patients reduce their symptom burden and improve their QOL [65].

Support from family, friends, HCP and community to carers is needed to help them cope during caring. HCP must explore diverse networks with different communities to come up with community volunteers or find existing community organizations to support these carers even at their homes.

\section{2) Physiological effects}

Physical problems experienced by carers include: pain, loss of physical strength, problems with sleep, appetite loss, loss of weight, grief, fatigue, hypertension, headaches, insomnia and eczema, and these are more common in women than in men [15] [41]. Caring for a cancer patient is very distressing and a long journey; patients go through long admissions because of the longevity of treatment for cancer, and being at the bedside for a long time causes carers to have physiological problems due to excessive fatigue and tiredness; this is evident when carers keep asking for painkillers as they suffer headaches during the hospital stay.

3) Social effects

Cancer treatment is very involving; carers end up experiencing social problems such as role strain, quitting employment, financial difficulties, transport difficulties to and from hospital, isolation and restrictions in social life because of the increased care needs of the patient and increased care burden [40] [42]. Carers of cancer patients often experience disruptions to their social and domestic activities due to the burden of caring tasks [57]. Total disruption of daily life is evident in carers of cancer patients and it affects social aspects such as employment and financial difficulties [48].

In Cancer Diseases Hospital, Lusaka, almost all cancer patients and their carers undergo social problems, because of the location of the cancer hospital in the capital city of Zambia. Patients come from all over the country to access cancer treatment, and the treatment timeframe for treating cancer is generally long. On a positive note, the Government of Zambia pays for treatment for all Zambian citizens so that they can access free treatment. Therefore, patients and their carers just pay for transport to the cancer hospital, daily self-care, diagnostic services and food, because accommodation is free, unless one wants to benefit from high cost services which are charged. Due to expenses of food and diagnostic services, carers and patients tend to deplete resources until they do not even have transport money to go back to their home town. The social welfare unit then comes in to assist these families with transport money from hospital budgets for social welfare of cancer patients and their families. Social welfare, diagnosis and care services must be planned and put in place in hospital to ensure that cancer patients and their families are taken care of adequately.

4) Carers' coping mechanisms

Coping strategies used by carers include: turning to God, keeping busy with 
housework, taking straws, playing games on the computer, crying, thanking God, being with friends, watching movies, performing handiworks and praying. Informal support has a positive effect on carers' coping styles [15] [34] [40] [42]. Different carers express different coping strategies; some carers employ negative coping mechanisms such as excessive alcohol consumption. Some use coping strategies such as talking to friends and praying while using faith and self-control of emotions [48].

\subsubsection{Theme 4: Proper Coordination of Care among Providers}

1) Complaints about healthcare personnel and hospital conditions

Disagreements and lack of cooperation among HCP, long waiting times for treatment due to inadequate personnel, lack of recognition of carers' roles, uncomfortable conditions of hospital and insufficient equipment such as wheelchairs to ease patients' movement affect patients and carers negatively [39] [42] [43]. HCP do not recognise the role of carers of cancer patients, which is devastating to them [52]. Carers have many needs which are not identified and met by HCP [64].

\section{2) Education and involvement of the patient and carer in healthcare}

Education and active involvement of patients and carers is important to enable them to be well informed to understand the disease, its prognosis, signs and symptoms, pain medication choices, available treatment, and treatment modalities, side-effects and management, as this enables them to be active and have control over their illness [42] [43]. Carers are often ignorant about the patient's cancer condition and if HCP have not taken time to educate them, they will not be able to identify and manage basic symptoms [64].

Some carers portray behaviours that indicate need to receive information from HCP so that they understand how to take care of their patients and relieve their uncertainty and anxiety about the disease; however, some carers do not show need to receive any information about their patient's illness as they are afraid of how they will react once they hear the bad news [66]. Support from HCP, family and friends positively influences carers [52].

\section{3) Fear of use of pain medication}

The intensity of pain has a direct negative effect on patients' QOL and not on partners' QOL [16] [43]. Patients' fears of the use of pain medication emerged from interviews and include: fear of opioids, addiction, being judged, being seen as a weakling for admitting pain, loss of control and expressing need for medication. Carers expressed fear of feeling unable to manage pain anymore and of thinking that opioids hasten the patient's death.

\subsection{Limitations of the Review}

Study limitations in the current review include difficulties of accessing relevant unpublished or grey literature. Only studies published in English language were included in the review, meaning that relevant studies published in other languages were not included. The number of good quality studies found to be in- 
cluded in the review was limited, and so relevant literature reviews were included; however, these tend to be vulnerable to reviewer biases [30]. The literature review was done independently by one researcher who was in training, and this meant that analysis by one independent individual was applied, and the study was not peer-reviewed by another researcher to achieve a balance. Effective analysis was achieved through use of a validated critical analysis tool. Constant supervision and guidance was sought from the research supervisor, creating an opportunity for questioning, challenging results, discussions and conclusions of the review [30].

Notwithstanding these limitations, the results of the current review provide a worthwhile and exceptional understanding of challenges that spouses of cancer patients face when caring for their patients with cancer and these results add to the existing body of knowledge in this area.

\subsection{Dissemination of Review Findings}

The review findings added to the current body of knowledge and dissemination of the findings to HCP is vital. Therefore, review findings were distributed to clinicians and colleagues, through presentations in clinical meetings, conferences and workshops, and through this publication.

\subsection{Recommendations for Future Research}

The review highlighted the need to integrate female carers of cancer patients to the healthcare system by promptly recognizing their roles, needs and challenges. More research is needed to find out more about effective support strategies that could improve female carers' QOL.

\section{Conclusion and Recommendations}

\subsection{Conclusion}

The first is quality of marital relationship, which states that female carers and their patients with cancer are directly affected by the cancer disease itself, symptoms, the period of admission in hospital and caring roles. Many challenges face women caring for a spouse having cancer treatment. Four key themes are: Quality of marital relationship (female carers and their patients are directly affected by the cancer, symptoms, period of admission in hospital and caring roles); Effective communication (female carers withhold information from spouses by not communicating openly with them as silence is perceived as protecting the patient and protecting their patient from additional stress; skills of reassurance, greeting and showing concern help carers and patients with cancer); Burdens related to caring (female carers of husbands with cancer experience poor quality of life, poor health and serious negative social and psychological effects); and Proper coordination of care among health care providers (HCP do not recognise the important role that female carers play for their patients and in the healthcare system, nor their needs, hence carers feel intimidated). 


\subsection{Healthcare Clinical Implications}

Female carers of cancer patients face several challenges, and this review creates a basis from which HCP will practise, to improve carers' QOL. HCP do not consider carers' role and needs; therefore, advocacy must be done to influence policy to integrate carers to the healthcare system. Policy guidelines should be put in place to guide HCP to care for not only patients but also their spouses. Challenges of carers of cancer patients must be promptly anticipated, identified and managed using the health care assessment system in clinical practice by HCP. HCP should be educated to appreciate the value and role of female carers of cancer patients, their needs and how to support them. HCP must facilitate for carers and their patients to express feelings openly between each other. Carers must be helped to understand their role for patients and how they can support them. HCP must identify carers' support groups and create networks to support carers effectively. In conclusion, the challenges of female carers must be identified and managed, to enable their access to healthcare services. Care services for carers will improve their QOL and patients' QOL.

\section{Operational Definitions}

Spouse: partner or wife of someone in the civil state of marriage, or who has lived with a patient for over 3 months or has been acknowledged by the patient as his or her partner.

Breadwinner: the person in a household who earns most money and supports the family most.

\section{Acknowledgements}

My God the Almighty for the gift of life and my medical career; my dear husband, friend Festus Simuunza and my sons Pascal, Nathanael, Jayson and Miguel Simuunza; Ministry of Health-Cancer Diseases Hospital.

\section{Conflicts of Interest}

The authors declare no conflicts of interest regarding the publication of this paper.

\section{References}

[1] Zambia National Cancer Registry (2018). http://afcrn.org/index.php/membership/membership-list/135-zambiacancerreigstry

[2] The African Cancer Registry Network (AFCRN) (2018) Cancer in Sub-Saharan Africa. https://afcrn.org/

[3] Globocan (2017) http://www.iacr.com.fr/index.php?option=com_content\&view=article\&id=101\&Ite $\underline{\operatorname{mid}=578}$

[4] De Vuyst, H., Alemany, L., Lacey, C., Chibwesha, C.J., Sahasrabuddhe, V., Banura, C., Denny, L. and Parham, G.P. (2013) The Burden of Human Papillomavirus Infections and Related Diseases in Sub-Saharan Africa. Vaccine, 31, F32-F46. https://doi.org/10.1016/j.vaccine.2012.07.092 
[5] Mukwato, K.P., Mweemba, P., Makukula, M.K. and Makoleka, M.M. (2010) Stress and Coping Mechanisms among Breast Cancer Patients and Family Caregivers: A Review of Literature. Medical Journal of Zambia, 37, 40-45.

[6] Bowa, K., Wood, C., Chao, A., Chintu, C., Mudenda, V. and Chikwenya, M. (2009) A Review of the Epidemiology of Cancers at the University Teaching Hospital, Lusaka, Zambia. Tropical Doctor, 39, 5-7. https://doi.org/10.1258/td.2008.070450

[7] Cancer diseases Hospital (2017) Annual Report for 2014. Lusaka, Zambia.

[8] Zambia National Cancer Registry (2015) http://afcrn.org/index.php/membership/membership-list/135-zambiacancerreigstry

[9] Gopalan, N. and Brannon, L.A. (2006) Increasing Family Members' Appreciation of Family Caregiving Stress. The Journal of Psychology, 140, 85-94. https://doi.org/10.3200/JRLP.140.2.85-94

[10] Hilton, B.A., Crawford, J.A. and Tarko, M.A. (2000) Men's Perspectives on Individual and Family Coping with Their Wives' Breast Cancer and Chemotherapy. Western Journal of Nursing Research, 22, 438-459.

[11] Hagedoorn, M., Sanderman, R., Coyne, J.C., Bolks, H.N. and Tuinstra, J. (2008) Distress in Couples Coping with Cancer: A Meta-Analysis and Critical Review of Role and Gender Effects. Psychological Bulletin, 134, 1-30. https://doi.org/10.1037/0033-2909.134.1.1

[12] Chen, M.L., Chu, L. and Chen, H.C. (2004) Impact of Cancer Patients' Quality of Life on that of Spouse Caregivers. Support Care Cancer, 12, 469-475. https://doi.org/10.1007/s00520-004-0636-Z

[13] Blanchard, C.G. (1997) The Crisis of Cancer: Psychological Impact on Family Caregivers.

http://www.cancernetwork.com/articles/crisis-cancer-psychological-impact-familycaregivers

[14] Edwards, B. and Clarke, V. (2004) The Psychological Impact of a Cancer Diagnosis on Families: The Influence of Family Functioning and Patients' Illness Characteristics on Depression and Anxiety. Psycho-Oncology, 13, 562-576. https://doi.org/10.1002/pon.773

[15] Nijboer, C., Triemstra, M., Tempelaar, R., Mulder, M., Sanderma, R. and Bos, G.A.M. (2000) Patterns of Caregiver Experiences among Partners of Cancer Patients. The Gerontological Society of America, 40, 738-746. https://doi.org/10.1093/geront/40.6.738

[16] Morgan, M.A., Small, B.J., Donovan, K.A., Overcash, J. and McMillan, S. (2011) Cancer Patients with Pain: The Spouse/Partner Relationship and Quality of Life. Cancer Nursing, 34, 13-23. https://doi.org/10.1097/NCC.0b013e3181efed43

[17] Braun, M., Mikulincer, M., Rydall, A., Walsh, A. and Rodin, G. (2007) Hidden Morbidity in Cancer: Spouse Caregivers. Journal of Clinical Oncology, 25, 4829-4834. https://doi.org/10.1200/JCO.2006.10.0909

[18] Kim, Y. and Carver, C.S. (2007) Frequency and Difficulty in Caregiving among Spouses of Individuals with Cancer: Effects of Adult Attachment and Gender. Psycho-Oncology, 16, 714-723. https://doi.org/10.1002/pon.1110

[19] Rose-Rego, S.K., Strauss, M.E. and Smyth, K.A. (1998) Differences in the Perceived Well-Being of Wives and Husbands Caring for Persons with Alzheimer's Disease. The Gerontologist, 38, 224-230. https://doi.org/10.1093/geront/38.2.224

[20] Soothill, K., Morris, S.M., Harman, J.C., Francis, B., Thomas, C. and McIllmurray, M.B. (2001) Informal Carers of Cancer Patients: What Are Their Unmet Psychoso- 
cial Needs? Health and Social Care in the Community, 9, 464-475. https://doi.org/10.1046/j.0966-0410.2001.00326.x

[21] Brown, R.F., Shuk, E., Butow, P., Edgerson, S., Tattersall, M.H.N. and Ostroff, J.S. (2011) Patient Perception, Preference and Participation, Identifying Patient Information Needs about Cancer Clinical Trials Using a Question Prompt List. Patient Education and Counseling, 84, 69-77. https://doi.org/10.1016/j.pec.2010.07.005

[22] Sinfield, P., Baker, R., Ali, S. and Richardson, A. (2012) The Needs of Carers of Men with Prostate Cancer and Barriers and Enablers to Meeting Them: A Qualitative Study in England. European Journal of Cancer Care, 21, 527-534. https://doi.org/10.1111/j.1365-2354.2012.01341.x

[23] Berry, L.L., Dalwadi, S.M. and Jacobson, J.O. (2016) Supporting the Supporters: What Family Caregivers Need to Care for a Loved One with Cancer. American Society of Clinical Oncology, 13, 35-41. https://doi.org/10.1200/JOP.2016.017913

[24] Beaver, K. and Witham, G. (2007) Information Needs of the Informal Carers of Women Treated for Breast Cancer. European Journal of Oncology Nursing, 11, 16-25. https://doi.org/10.1016/j.ejon.2006.01.006

[25] Kvale, K. (2007) Do Cancer Patients Always Want to Talk about Difficult Emotions? A Qualitative Study of Cancer Inpatients Communication Needs. European Journal of Oncology Nursing, 11, 320-327. https://doi.org/10.1016/j.ejon.2007.01.002

[26] Cornwell, P., Dicks, B., Fleming, J., Haines, T.P. and Olson, S. (2012) Care and Support Needs of Patients and Carers Early Post-Discharge Following Treatment for Non-Malignant Brain Tumour: Establishing a New Reality. Support Care Cancer, 20, 2595-2610. https://doi.org/10.1007/s00520-012-1383-1

[27] Kim, H. and Yi, M. (2015) Unmet Needs and Quality of Life of Family Caregivers of Cancer Patients in South Korea. Asia-Pacific Journal of Oncology Nursing, 2, 152-159. https://doi.org/10.4103/2347-5625.158019

[28] Aveyard, H. (2014) Doing a Literature Review in Health and Social Care a Practical guide. 3rd Edition, Open University Press, Maidenhead, Berkshire.

[29] Aveyard, H. and Sharp, P. (2013) A Beginner's Guide to Evidence Based Practice 2nd Edition, Open University Press, Maidenhead, Berkshire.

[30] Bowling, A. (2014) Research Methods in Health. 4rd Edition, Oxford University Press-McGraw Hill Education, Oxford.

[31] Crowther, M., Lim, W. and Crowther, M.A. (2010) Systematic Review and MetaAnalysis Methodology. Blood, 116, 3140-3146. https://doi.org/10.1182/blood-2010-05-280883

[32] Smith, L. and Dixon, L. (2009) Systematic Reviews. In: Neale, J., Ed., Research Methods for Health and Social Care, Palgrave Macmillan, Basingstoke, 63-77.

[33] Critical Appraisal Skills Programme (CASP) (2018) Systematic Review Checklist. https://casp-uk.net/wp-content/uploads/2018/03/CASP-Systematic-Review-Checkli st-2018_fillable-form.pdf

[34] Critical Appraisal Skills Programme (CASP) (2018) Qualitative Study Checklist. https://casp-uk.net/wp-content/uploads/2018/01/CASP-Qualitative-Checklist-2018. pdf

[35] Critical Appraisal Skills Programme (CASP) (2018) Cohort Study Checklist. https://casp-uk.net/wp-content/uploads/2018/01/CASP-Cohort-Study-Checklist_20 18.pdf

[36] Bettany-Saltikov, J. (2012) How to Do a Systematic Literature Review in Nursing: A 
Step-by-Step Guide. Open University Press, Maidenhead, Berkshire.

[37] Creswell, J.W. (2007) Qualitative Inquiry and Research Design-Choosing among Five Approaches. 2nd Edition, Sage Publications, Inc., Newbury Park, CA.

[38] Pitceathly, C. and Maguire, P. (2003) The Psychological Impact of Cancer on Patients' Partners and Other Key Relatives: A Review. European Journal of Cancer, 39, 1517-1524. https://doi.org/10.1016/S0959-8049(03)00309-5

[39] Mossin, H. and Landmark, B.T. (2011) Being Present in Hospital When the Patient Is Dying-A Grounded Theory Study of Spouses Experiences. European Journal of Oncology Nursing, 15, 382-389. https://doi.org/10.1016/j.ejon.2010.11.005

[40] Li, Q. and Loke, A.Y. (2013) A Literature Review on the Mutual Impact of the Spousal Caregiverecancer Patients Dyads: 'Communication', 'Reciprocal Influence', and 'Caregiverepatient Congruence'. European Journal of Oncology Nursing, 18, 58-65. https://doi.org/10.1016/j.ejon.2013.09.003

[41] Li, Q.P., Mak, Y.W. and Loke, A.Y. (2013) Spouses' Experience of Caregiving for Cancer Patients: A Literature Review. International Nursing Review, 60, 178-187. https://doi.org/10.1111/inr.12000

[42] Sercekus, P., Besen, D.B., Gunusen, N.P. and Edeer, A.D. (2014) Experiences of Family Caregivers of Cancer Patients Receiving Chemotherapy. Asian Pacific Journal of Cancer Prevention, 15, 5063-5069. https://doi.org/10.7314/APJCP.2014.15.12.5063

[43] Kimberlin, C., Brushwood, D., Allen, W., Radson, E. and Wilson, D. (2004) Cancer Patient and Caregiver Experiences: Communication and Pain Management Issues. Journal of Pain and Symptom Management, 28, 566-578. https://doi.org/10.1016/j.jpainsymman.2004.03.005

[44] Stenberg, U., Ekstedt, M., Olsson, M. and Ruland, C.M. (2014) Living Close to a Person with Cancer: A Review of the International Literature and Implications for Social Work Practice. Journal of Gerontological Social Work, 57, 531-555. https://doi.org/10.1080/01634372.2014.881450

[45] Moser, M.T., Künzler, A., Nussbeck, F., Bargetzi, M. and Znoj, H.J. (2013) Higher Emotional Distress in Female Partners of Cancer Patients: Prevalence and Patient-Partner Interdependencies in a 3-Year Cohort. Psycho-Oncology, 22, 2693-2701. https://doi.org/10.1002/pon.3331

[46] Mystakidou, K., Parpa, E., Panagiotou, I., Tsilika, E., Galanos, A. and Gouliamos, A. (2013) Caregivers' Anxiety and Self-Efficacy in Palliative Care. European Journal of Cancer Care, 22, 188-195. https://doi.org/10.1111/ecc.12012

[47] Carlson, L., Bultz, B., Speca, M. and St. Pierre BA, M. (2000) Partners of Prostate Cancer Patients: Part 1. Impact, Adjustment, and Coping across the Illness Trajectory. Journal of Psychosocial Oncology, 18, 39-63. https://doi.org/10.1300/J077v18n02_03

[48] Houldin, A.D. (2007) A Qualitative Study of Caregivers' Experiences with Newly Diagnosed Advanced Colorectal Cancer. Oncology Nursing Forum, 34, 323-330. https://doi.org/10.1188/07.ONF.323-330

[49] Braun, M., Hales, S., Gilad, L., Mikulicer, M., Rydall, A. and Rodin, G. (2012) Caregiving Styles and Attachment Orientations in Couples Facing Advanced Cancer. Psycho-Oncology, 21, 935-943. https://doi.org/10.1002/pon.1988

[50] LeSeure, P. and Chongkham-Ang, S. (2015) The Experience of Caregivers Living with Cancer Patients: A Systematic Review and Meta-Synthesis. Journal of Personalized Medicine, 5, 406-439. https://doi.org/10.3390/jpm5040406 
[51] Kim, Y., Carver, C.S., Deci, E.L. and Kasser, T. (2008) Adult Attachment and Psychological Well-Being in Cancer Caregivers: The Mediational Role of Spouses' Motives for Caregiving Health Psychology, 27, S144-S154.

[52] Turner, M., King, C., Milligan, C., Thomas, C., Brearley, S.G., Seamark, D., Wang, X., Blake, S. and Payne, S. (2016) Caring for a Dying Spouse at the End of Life: 'It's One of the Things You Volunteer for When You Get Married': A Qualitative Study of the Oldest Carers' Experiences. Age and Ageing, 45, 421-426. https://doi.org/10.1093/ageing/afw047

[53] Coristine, M., Crooks, D., Grunfeld, E., Stonebridge, C. and Christie, A. (2003) Caregiving for Women with Advanced Breast Cancer. Psycho-Oncology, 12, 709-719. https://doi.org/10.1002/pon.696

[54] Andershed, B. and Ternestedt, B.M. (1998) Involvement of Relatives in the Care of the Dying in Different Care Cultures, Involvement in the Dark or in the Light? Cancer Nursing, 21, 106-116. https://doi.org/10.1097/00002820-199804000-00004

[55] Pearce, M.P., Singer, J.L. and Prigerson, H.G. (2006) Religious Coping among Caregivers of Terminally Ill Cancer Patients. Main Effects and Psychosocial Mediators. Journal of Health Psychology, 11, 743-759. https://doi.org/10.1177/1359105306066629

[56] Olson, R.E. (2014) Indefinite Loss: The Experiences of Carers of a Spouse with Cancer. European Journal of Cancer Care, 23, 553-561. https://doi.org/10.1111/ecc.12175

[57] Resendes, L.A. and McCorkle, R. (2006) Spousal Responses to Prostate Cancer: An Integrative Review. Cancer Investigation, 24, 192-198. https://doi.org/10.1080/07357900500524652

[58] Campbell, H.S., Sanson-Fisher, R., Taylor-Brown, J., Hayward, L., Wang, X.S. and Turner, D. (2009) The Cancer Support Person's Unmet Needs Survey. Cancer, 115, 3351-3359. http://onlinelibrary.wiley.com/doi/10.1002/cncr.24386/pdf https://doi.org/10.1002/cncr.24386

[59] Adams, E., Boulton, M. and Watson, E. (2009) The Information Needs of Partners and Family Members of Cancer Patients: A Systematic Literature Review. Patient Education and Counseling, 77, 179-186.

http://www.sciencedirect.com/science/article/pii/S0738399109001487\# https://doi.org/10.1016/j.pec.2009.03.027

[60] Tamayo, G.J., Broxson, A., Munsell, M. and Cohen, M.Z. (2010) Caring for the Caregiver. Oncology Nursing Forum, 37, E50-E57. https://doi.org/10.1188/10.ONF.E50-E57

[61] Duggleby, W., Tycholiz, J., Holtslander, L., Hudson, P., Nekolaichuk, C., Mirhosseini, M., Parmar, J., Chambers, T., Alook, A. and Swindle, J. (2017) A Metasynthesis Study of Family Caregivers' Transition Experiences Caring for Community-Dwelling Persons with Advanced Cancer at the End of Life. Palliative Medicine, 31, 602-616. https://doi.org/10.1177/0269216316673548

[62] Sanders, S., Pedro, L.W., Bantum, E.O. and Galbraith, M.E. (2006) Couples Surviving Prostate Cancer: Long-Term Intimacy Needs and Concerns Following Treatment. Clinical Journal of Oncology Nursing, 10, 503-508.

https://doi.org/10.1188/06.CJON.503-508

[63] Andrade, L., Gorenstein, C., Vieira Filho, A.H., Tung, T.C. and Artes, R. (2001) Psychometric Properties of the Portuguese Version of the State-Trait Anxiety Inventory Applied to College Students, Factor Analysis and Relation to the Beck Depression Inventory. Brazilian Journal of Medicine and Biology Research, 34, 
367-374. https://doi.org/10.1590/S0100-879X2001000300011

[64] Levesque, J.V., Smith, A.B., Durcinoska, I. and Gerges, M. (2017) The Role and Supportive Care Needs of the Partners and Carers of Women with Breast Cancer. Cancer Forum, 41, 1-8.

[65] Northouse, L., Williams, A., Given, B. and McCorkle, R. (2012) Psychosocial Care for Family Caregivers of Patients with Cancer. Journal of Clinical Oncology, 30, 1227-1234. https://doi.org/10.1200/JCO.2011.39.5798

[66] Feltwell, A.K. and Rees, C.E. (2004) The Information-Seeking Behaviours of Partners of Men with Prostate Cancer: A Qualitative Pilot Study. Patient Education and Counseling, 54, 179-185. https://doi.org/10.1016/S0738-3991(03)00212-X

\section{List of Acronyms/Abbreviations}

CASP Critical Appraisal Skills Programme

$\mathrm{CDH} \quad$ Cancer Diseases Hospital

QOL Quality of Life

HBC Home-Based Care

PC Palliative Care

HCP Healthcare Personnel

ZNCR Zambia National Cancer Registry

AIDS Acquired Immunodeficiency Syndrome

HIV Human Immunodeficiency Virus 